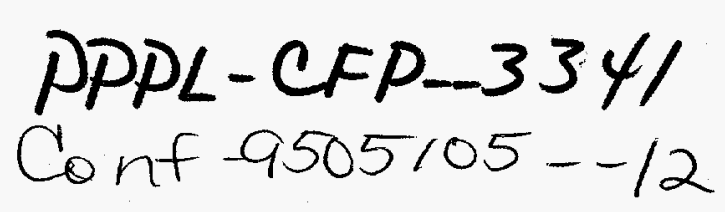

\title{
A Modified Lower Hybrid Coupler for TPX.
}

\author{
Stefano Bernabei, Paul Goranson *, Nevell Greenough and \\ David Swain *. \\ Princeton Plasma Physics Laboratory, P.O.Box 451 Princeton, N.J. 08543 \\ * Oak Ridge National Laboratory
}

Efforts have concentrated on redesigning the configuration of the Lower Hybrid coupler for the TPX tokamak. Several concerns motivated this redesign: reduce the effect of thermal incompatibility between coupler and if-window material, reduce weight, reduce the risk of window failure and address the problem of replaceability, increase the reliability by reducing the number of connections and finally, reduce the total cost. The result is a highly compact, light and easily serviceable coupler which incorporates some of the simplicity of the multijunction coupler but preserves the spectral flexibility of a conventional coupler.

\section{INTRODUCTION}

The Lower Hybrid Current Drive system for TPX consists of $4 \mathrm{MW}$ of power at $3.7 \mathrm{GHz}$, for a pulse length of 1000 seconds. Since the Conceptual Design Review [1], design changes have been made to the lower hybrid coupler, to eliminate thermal incompatibilities, improve reliability, reduce complexity, and permit maintenance on the vacuum windows. As a result of the changes the coupler weight has been reduced by $16000 \mathrm{lbs}(7272 \mathrm{~kg})$ from the original $31500 \mathrm{lbs}$ and costs reduced significantly. Reduction in the TPX operating temperature to $65^{\circ} \mathrm{C}$ will permit the use of water as neutron shielding, further reducing cost and complexity. Neutronic analysis has been performed [2] which indicate that staggering waveguides to reduce neutron streaming is not necessary; the result being that the overall height is reduced and the coupler can fit into any of the standard TPX ports.

\section{COUPLER DESCRIPTION}

The coupler consists of eight waveguide arrays, configured in four rows and two columns. Each array is comprised of 32 phased waveguides for a total of 256 waveguides. Each waveguide measures $76 \times 6 \mathrm{~mm}^{2}$ and is expected to transmit 12 $\mathrm{kW}$, corresponding to $2.6 \mathrm{~kW} / \mathrm{cm}^{2}$. The coupler is fed by only 64 waveguides at the vessel port interface; this is accomplished by incorporating a vertical four-way power splitter into the array. Figure 1 shows an elevation cut of the coupler: each of the 64 standard waveguides has a full size window, followed by a transformer to reduce the width to the desired size. Three $3 \mathrm{~dB}$ dividers split the power in four ways vertically. Therefore each of the 32 waveguides in any individual grill is independently phased. Because of space constraint the fourth port of the splitter is shorted; this may cause some phase error when the reflection from the four vertical ports is uneven. A simple analysis shows that this error does not impact seriously on the launched spectrum. A more rigorous analysis is underway.

Forward and reflected power are monitored in the top and bottom channels of the coupler and in each of the 64 feed waveguides. This configuration should be adequate provided that the plasma density and position are similar for all four sections of the coupler. Two coupling loops will be placed in the side wall of the waveguide, one quarter of wave apart. Signals from the loops will exit the coupler on vacuum compatible $\mathrm{SiO}_{2}$ cable. $\mathrm{A} 90^{\circ}$ hybrid will resolve the two signals into forward and reflected components. 


\section{DISCLAIMER}

This report was prepared as an account of work sponsored by an agency of the United States Government. Neither the United States Government nor any agency thereof, nor any of their employees, makes any warranty, express or implied, or assumes any legal liability or responsibility for the accuracy, completeness, or usefulness of any information, apparatus, product, or process disclosed, or represents that its use would not infringe privately owned rights. Reference herein to any specific commercial product, process, or service by trade name, trademark, manufacturer, or otherwise does not necessarily constitute or imply its endorsement, recommendation, or favoring by the United States Government or any agency thereof. The views and opinions of authors expressed herein do not necessarily state or reflect those of the United States Government or any agency thereof. 


\section{DISCLAIMER}

Portions of this document may be illegible in electronic image products. Images are produced from the best available original document. 


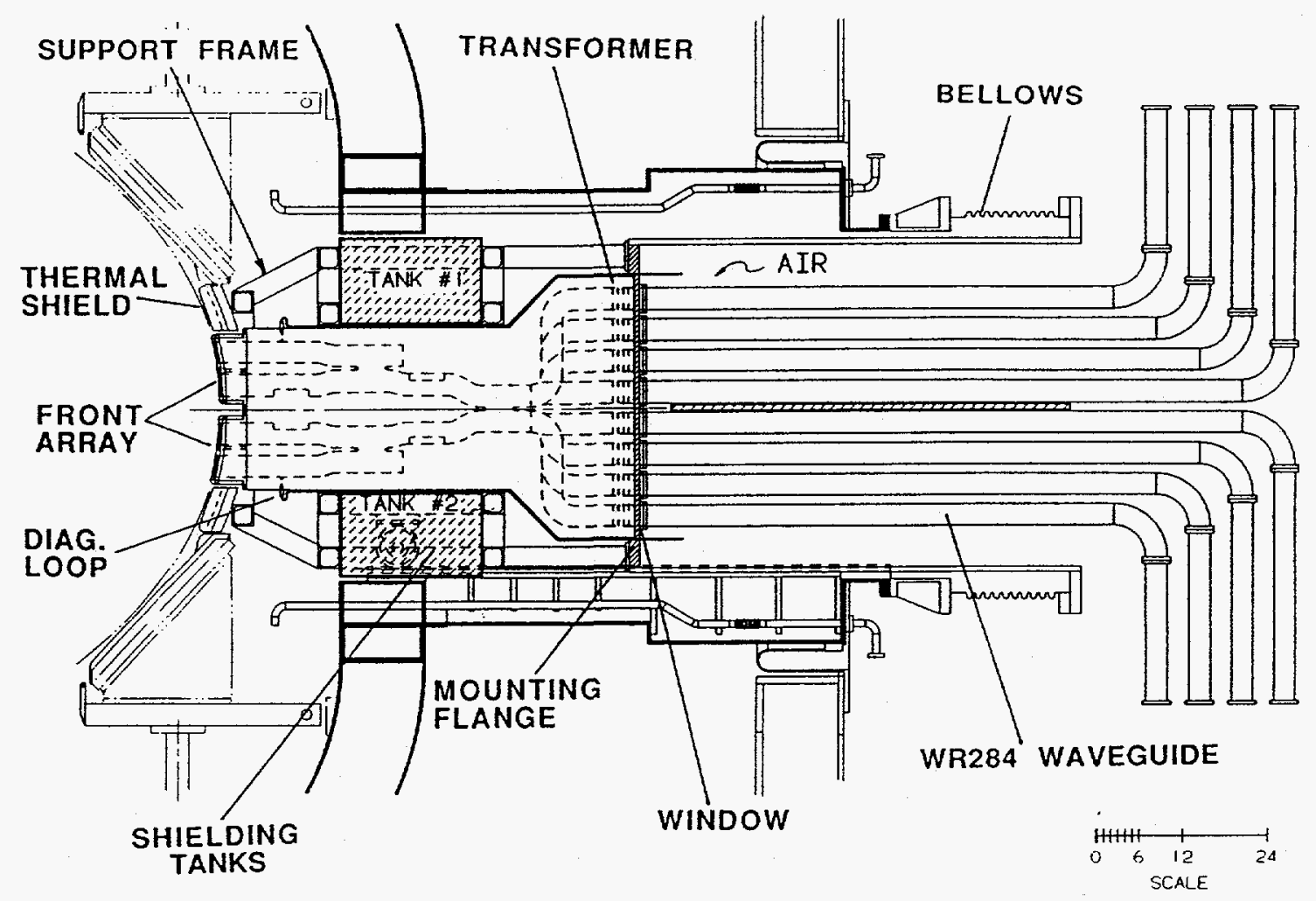

FIG. 1 ELEVATION VIEW OF THE LH COUPLER

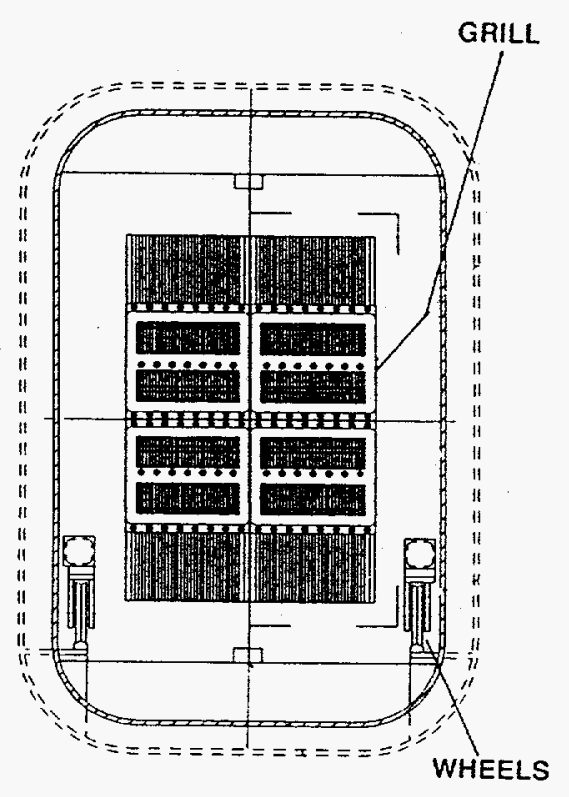

FIG. 2 FRONT VIEW

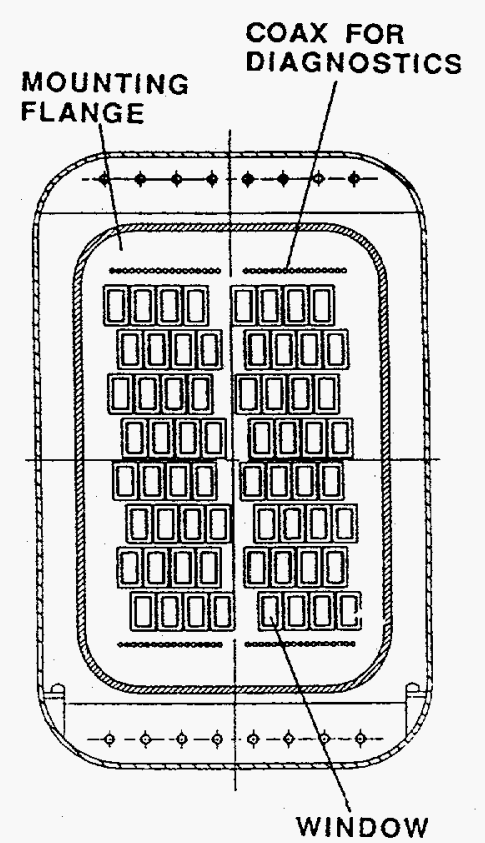

FIG. 3 REAR VIEW AT THE MOUNTING FLANGE 


\section{MECHANICAL DESIGN DESCRIPTION}

The coupler is a radially moveable unit supported by wheels at the front (plasma end) and restrained radially by a set of 4 positioning screw drive units at the port end, which react loads into the vessel through the vacuum vessel flange. The coupler is isolated from vacuum by a single bellows at the cryostat mounting flange. A re-entrant vessel moves the vacuum interface within the vessel port, at the vacuum window. A framework constructed of low activation titanium alloy serves as a backbone structure to tie together and hold the various components. Surfaces of the coupler which directly view plasma are provided with a protective coating of flame coated $\mathrm{B}_{4} \mathrm{C}$ to prevent sputtering damage. Tanks of water shielding are provided to fill the gaps between the coupler and the port walls.

\section{COMPONENT DESIGN}

The grilles bolt onto the front array. The units are designed to be EDM'd from solid plate, followed by machining to final contour and drilling for water passages (Fig. 2). The outer perimeter which may contact plasma is protected by a layer of carbon-carbon tiles, $1.6 \mathrm{~mm}$ thick, brazed to the metal surface. The septa are very thin and long ( $2 \mathrm{~mm}$ by $76 \mathrm{~mm}$ ) and are not practical to port for cooling passages.

This forces all cooling to be done by conduction across the septa into top and bottom coolant paths. Thermal analysis resulted in the baseline design choice of GlidCop coated with $\mathrm{B}_{4} \mathrm{C}$.

The transition the array from eight rows to four rows permits wide enough spacing at the rear of the array to allow mechanical bolting of individual waveguides to the vacuum window units (Fig. 3). The array is constructed by laminating a stack of copper plates, each with waveguide patterns milled into one side. The patterns are made identically except for the positioning of the rear exit (at the window). The completed unit is furnace brazed with a high temperature braze alloy to make it water tight.

After brazing, the front array is cross-drilled for coolant lines, the tubes are inserted, the coolant headers installed and the unit brazed again, this time with a lower temperature braze alloy. The third step is to install a stainless steel flange at the rear and braze with a third alloy. This flange serves as the vacuum interface for the re-entrant vessel and as the interface for the vacuum windows. Stainless was chosen to permit a good vacuum seal with metal o-rings.

Formerly the windows were an integral assembly of sixteen individual windows brazed into a titanium frame. The titanium unit bolted to the copper front array and the two were thermally incompatible during bakeout. A suitable way of eliminating this problem was never found. The vacuum windows are now single element units which serve as the waveguide vacuum boundary. The small physical dimensions of the window and the fact they are bolted to individual waveguides virtually eliminates the thermal problems; the worst case mismatch is now only 0.0047 inches $(0.12 \mathrm{~mm})$. Their construction is basically a commercial design based on the WR-284 configuration. The window unit has sufficient material thickness so that it could be cross-drilled to provide coolant through the septa as well as along the top and bottom, if required, but preliminary analysis indicates that forced air cooling should be sufficient..

The waveguides are another change to the design. Water cooling is no longer necessary with the waveguides in air; commercial WR-284 design units can be used. They are flanged at both ends and use metallic o-rings seals.

During bakeout at $350 \mathrm{C}$ the water shielding will be drained out or cooled to maintain $65 \mathrm{C}$. Designing the tanks for high pressure is not required. 


\section{ASSEMBLY AND INSTALLATION}

During handling and installation into the vessel port, the launcher can be rolled on its two front wheels while being suspended from its rear mount flange. The launcher front wheels engage tracks on the vessel port floor. As the launcher nears its nominal operation position, the unit's upper and lower keyways ride onto tapered guides which force alignment with the keys. The launcher wheels are provided with floating axles which permit free rotation of the launcher during disruptions.

\section{MAINTENANCE}

If changeout of a launcher should become necessary, the radiation shielding is designed to permit personnel access to the vessel flange and the launcher/power splitter interface. This will allow unbolting of the flanges and disconnecting the various utilities. The launcher front structure will be highly activated, therefore the final removal step will require remotely rolling the assembly into a handling cask and transporting it to a hot cell.

The grill is the component subjected to the most extreme operating conditions and it will eventually require renewal of its coating. It is designed to be easily accessible and replacement will be possible in a hot cell. Removal will entail cutting of two water leads and unbolting the grill. Installation of a new unit requires rewelding of the water leads or the use of shrink-type fittings.

The vacuum window design has a history of high reliability in several machines [3] and failures are expected to be rare. If a leak or short should develop in one of the elements, replacement will now be possible without removing the launcher. Access is through the vessel port flange. By removing one or more waveguides, a long tool can be used to unbolt the window and install a replacement. The exact number of removal operations and scope of the operation for any particular window is under study.

\section{ISSUES}

Construction of the launcher is dependent on the successful fabrication of a compact, laminated front array/splitter. Copper was chosen for its high thermal conductivity and its ease of brazing. Recent disruption analysis indicates that loads will be manageable. The present design requires three different braze operations at different temperatures; this is being studied to see if the assembly could be changed or modified and one of the brazing steps eliminated.

\section{AKNOWLEDGMENTS}

Work supported by U. S. Department of Energy contract number DE-AC02$76 \mathrm{CHO} 3073$

\section{REFERENCES}

[1] P. Goranson et al.: Conceptual Design of the LHCD-LHH Launcher for TPX.

Proc. of 15th IEEE/NPSS Sym. on Fus. Eng., p.380, Hyannis Mass. (Oct 1993)

[2]. L. P. Ku: LH Radiation Shielding. PPPL Engineering Analysis Division Report \#94-940712-PPPL/LKU-01

[3]. R. Walls, S. Bernabei and H. E. Evans: Fabrication of Phased Array Microwave Waveguide Windows in Proc. of the IEEE Conf. on Plasma Science, Knoxville, TN, Sept. 1989 